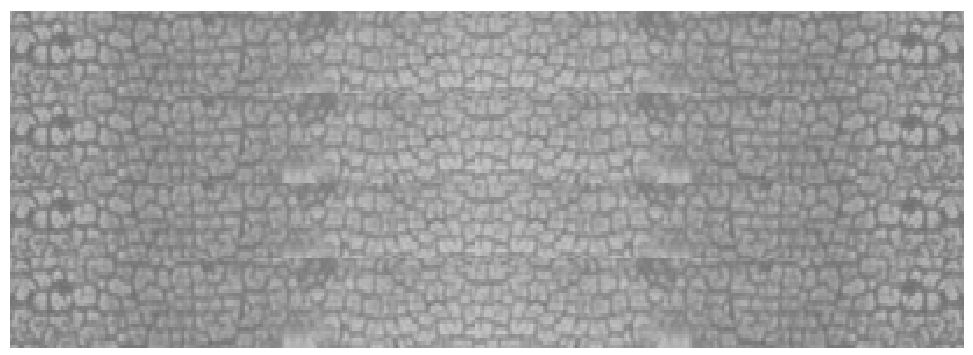

\title{
A construção coletiva da Biblioteca Virtual em Saúde*
}

Abel Laerte Packer ${ }^{1}$

PACKER, A. L. The collective construction of the Virtual Healthcare Library. Interface - Comunic., Saúde, Educ., v.9, n.17, p.249-72, mar/ago 2005.

The origin of the Virtual Healthcare Library $(\mathrm{VHL})$ as a product of the evolution of the technical cooperation program for scientific information on healthcare in Latin America and the Caribbean is resumed in this article. We analyze its technological structure as a product of the restructuring of the scientific community spurred by the Internet, stressing the conceptual and operational improvement of the model of collective management of information and knowledge within the virtual arena and the challenges of fostering democratic access and use of information and updated knowledge in the processes that involve collective and individual healthcare.

KEY WORDS: virtual library; medical libraries; information systems; collective intelligence.

Retoma-se a origem da Biblioteca Virtual em Saúde (BVS) como produto da evolução do programa de cooperação técnica em informação científica em saúde na América Latina e no Caribe. Analisa-se sua conformação tecnológica como produto da reestruturação da comunicação científica promovida pela internet, destacando o aprimoramento conceitual e operacional do modelo de gestão coletiva de informação e conhecimento no espaço virtual $e$ os desafios de promover o acesso e uso democráticos da informação e do conhecimento atualizado nos processos que envolvem a saúde coletiva e individual.

PALAVRAS-CHAVE: biblioteca virtual; bibliotecas médicas; sistemas de informação; inteligência coletiva.

\footnotetext{
${ }^{*}$ Agradeço a colaboração de Renata Ciol e Regina Castro.

${ }^{1}$ Diretor BIREME/OPAS/OMS, Centro Latinoamericano e do Caribe de Informação, Organização Panamericana de Saúde, Organização Mundial da Saúde, São Paulo, SP. <packerab@bireme.ops-oms.org>
} 
A proposta da Biblioteca Virtual em Saúde (BVS), como espaço virtual de convergência na Internet do trabalho cooperativo em informação científica $e$ técnica em saúde, foi aprovada em março de 1998, na $5^{\text {a }}$ Reunião do Sistema Latino-Americano e do Caribe de Informação em Ciências da Saúde, realizada em São José, Costa Rica, que contou com a participacão de representantes do sistemas nacionais de informação científica e técnica em saúde de todos os países da América Latina e da grande maoria das ilhas dos Caribe. Em conjunto, acordaram registrar o lançamento da BVS na Declaração de São José Rumo à Biblioteca Virtual em Saúde, comprometendo-se com sua construção coletiva (BIREME, 1998; Packer \& Castro, 1998).

A BVS é produto da evolução de três décadas do programa de cooperação técnica em informação científica na América Latina e Caribe. Sob a liderança da OPAS/OMS, o programa é coordenado e implantado pela BIREME, seu centro especializado, desde a sua criação em 1967. Na sua evolução, o programa adotou sucessivos paradigmas de gestão e operação de produtos e serviços na estrutura da comunicação científica, sempre funcionando em rede e buscando atender às necessidades de informação do sistemas nacionais de pesquisa, ensino e atenção à saúde. O programa iniciou-se com a rede de bibliotecas especializadas, enriquecida anos mais tarde com as funções de centros de informação $e$ indexação, a seguir como sistema de sistemas nacionais de informação e, a partir de 1998, com a biblioteca virtual operando na Internet. Seu portal operado pela BIREME está no sítio <www.bsaude.org>.

A BVS representa uma expansão radical dos modelos anteriores de gestão de informação e conhecimento em saúde e traz consigo inovações e desafios. Por um lado, a BVS expande a rede de cooperação a todas as instâncias e aos atores da comunicação cientifica e técnica. Por outro lado, expande também a natureza das redes de fontes e fluxos de informação no seu espaço, incluindo, agora, os domínios de informação e conhecimento cientifico, técnico, factual e tácito. Como biblioteca dinâmica no espaço virtual, a BVS pode ser visualizada como uma expansão da nossa memória, para acesso e registro de informação, $e$ como expressão da inteligência coletiva (Lévy, 1998, 1993). Nesse sentido, a BVS serve aos processos de saúde coletiva e individual, incluindo autoridades, gestores, pesquisadores, profissionais, trabalhadores, estudantes, usuários $e$ população em geral.

A construção da BVS, há sete anos do seu lançamento, é apresentada neste documento, retomando sua origem como produto da evolução do programa de cooperação técnica em informação científica em saúde na América Latina e no Caribe. Analisamos sua conformação tecnológica como produto da reestruturação da comunicação científica promovida pela Internet, destacando o aprimoramento conceitual e operacional do modelo de gestão coletiva de informação e conhecimento no espaço virtual e os desafios de promover o acesso eqüitativo e o uso ubiquo de informação e conhecimento atualizado nos processos que envolvem a saúde coletiva $e$ individual.

\section{A reestruturação da comunicação científica}

A principal força que impulsiona a construção coletiva da BVS como espaço de domínio público deriva da reestruturação que a Internet, como meio de publicação, vem promovendo na comunicação em geral e nos resultados da pesquisa científica, em particular. Na BVS, o conhecimento científico é tratado como um bem público. A nova estrutura em formação conduz à convergência

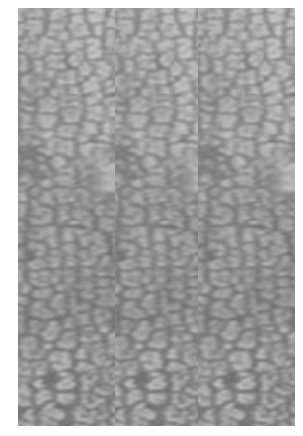


dos produtores, intermediários e usuários de informação no ciberespaço.

A publicação eletrônica on line na Internet, que inclui os periódicos científicos, desenvolveu-se aceleradamente na última década, com uma aceitação generalizada por parte de autores, publicadores, bibliotecários $e$ usuários. As primeiras resistências, ligadas à defesa do papel como suporte de registro e publicação, foram paulatinamente superadas devido às extraordinárias facilidades, potencialidades e conveniência oferecidas pelo acesso on line aos artigos e outros textos.

O que está em marcha não é a simples mudança do suporte papel para o suporte digital, mas um novo modo de produção do fluxo de informação na comunicação científica, com a emergência de movimentos para a publicação em acesso aberto (open access) e auto-arquivamento (self-archiving), que favorecem o acesso equitativo ao conhecimento científico. Esta restruturação tem caráter internacional, e vem ao encontro dos objetivos dos programas de cooperação técnica em informação científica na América Latina e Caribe, liderados pela BIREME.

\section{A estrutura clássica da comunicação científica em suporte papel}

A comunicação científica clássica, em suporte papel, realiza-se por meio de fluxos de trabalho e informação estruturados sobre uma seqüência de instâncias distantes fisicamente, onde ocorrem eventos específicos, separados no tempo e realizados por diferentes atores. Ao longo das instâncias, o fluxo de informação e trabalho que realizam os diferentes atores (autor, editor, revisor, indexador, bibliotecário, usuário-leitor) é conduzido por meio de documentos em papel que são transportados fisicamente de uma instância a outra.

A Figura 1 apresenta um esquema simplificado desta estrutura clássica, onde se podem identificar sete eventos principais no fluxo de informação e de trabalho, envolvendo atores e instâncias específicas:

1 os autores preparam os manuscritos de seus trabalhos e os submetem a um periódico para avaliação;

2 os manuscritos são recebidos pelos editores científicos $e$, se adequados ao escopo do periódico, entram no processo de revisão por pares, cuja comunicação com os autores é intermediada pelos editores;

3 quando os manuscritos são aprovados, são editados e compostos em fascículos que seguem para impressão; caso contrário, são devolvidos;

4 as cópias impressas são distribuídas para o público leitor dos periódicos, incluindo assinantes individuais e institucionais. Entre as instituições destinatárias destacam-se, por sua relevância na sustentação do fluxo de informação, os serviços de indexação e as bibliotecas;

5 nos serviços de indexação, os textos dos artigos e outras comunicações são referenciados, isto é, são produzidos registros de metadados com a referência bibliográfica (registro de autor, título e número do periódico), palavras-chave e resumos;

6 nas bibliotecas e centros de documentação, as publicações são registradas nos catálogos e organizadas nas estantes da coleção e disponibilizadas para consulta;

7 os leitores ou usuários utilizam as bibliotecas $e$, com a ajuda dos índices ou bases de dados bibliográficas, localizam as referências bibliográficas e textos que respondem às suas demandas de informação. Quando a biblioteca não possui a publicação solicitada, recorre a outras coleções por meio de serviços de 
localização e processamento de cópias de documentos.

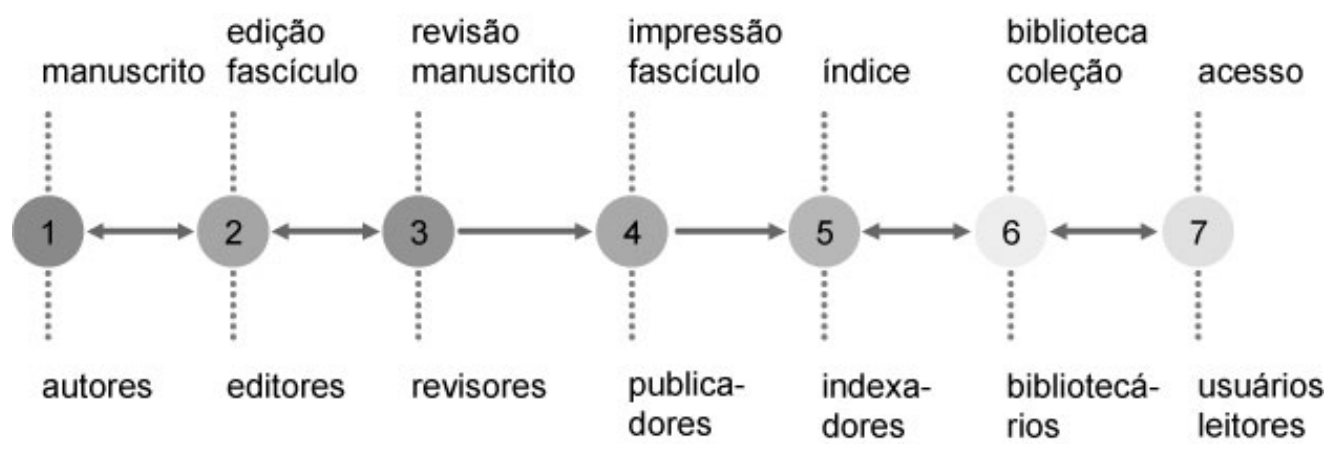

Figura 1. Estrutura clássica da comunicação científica em suporte papel. Os eventos, atores e instâncias ocorrem separadamente no espaço e no tempo.

A seqüência acima foi continuamente aperfeiçoada desde o aparecimento dos primeiros periódicos no século XVII, há 340 anos.

Nesta estrutura, a biblioteca, ou suas versões na forma de centros de documentação ou centros de informação, representa a penúltima instância de intermediação do texto e os seus usuários. A biblioteca é a instância que dá sustentação e democratiza o fluxo de informação ao funcionar como um repositório de publicações organizadas e preservadas para o seu uso repetido.

A função da publicação e da biblioteca pode ser interpretada como uma extensão da memória do ser humano. Nessa condição, sua origem está associada à evolução da linguagem e da comunicação, da capacidade do ser humano em registrar, congelar e escrever a fala (MacGarry, 1999). A passagem da tradição oral para a escrita, que pode ser identificada como o "despegar de la cultura", ocorre com uma dimensão objetiva:

Es el universo exterior extrasomático, que el lenguaje crea al modificar el medio, imprimiendo en él sus mensajes. ... Es la forjación del 'cerebro exterior'. Así como la técnica a través de los instrumentos nos dotaba de órganos nuevos y más poderosos, ahora el cerebro exterior - que es el lenguaje - permite socializar los hallazgos de la actividad cerebral creadora, de sus experiencias, y constituir un patrimonio colectivo de posibilidades, una memoria externa. Su fijación y mantenimiento ha definido todo un capítulo central de la historia humana. (Paris, 2000, p.252)

\section{Como memória externa,}

não basta apenas ser capaz de armazenar informação fora do cérebro; ela deve ser armazenada de modo organizado para que se possa voltar a utilizá-la. Desde o passado mais longínquo a que se pode recuar com alguma certeza, sempre houve locais especificamente construídos com esse fim. As bibliotecas, em seu sentido mais amplo, existem há quase tanto tempo quanto os próprios registros escritos. Qualquer que seja a sua forma externa, a 
essência de uma biblioteca é uma coleção de materiais organizados para uso. (McGarry, 1999, p.111)

Os seres humanos morremos, mas o que escrevemos fica armazenado $e$ indexado na biblioteca. Nascemos e, em vida socializamos, equipados com a biblioteca, o que nos lega escrito a humanidade. A biblioteca é, portanto, parte integral da evolução da vida em sociedade, da reprodução de informação e de conhecimento que sustenta a evolução cultural, incluindo particularmente o domínio científico e técnico que se desenvolve com a linguagem e a comunicação científica. A expressão mais nobre da comunicação científica são os artigos originais publicados nos periódicos científicos.

A biblioteca, em sentido amplo, pode ser entendida como a instância que daria acesso a todas as publicações. Entretanto, esta perspectiva, embora desejada e sonhada, é impossível de realizar-se na estrutura clássica da comunicação científica, pois apresenta limitações intrínsecas que impedem o acesso universal aos textos e, em particular, aos resultados das pesquisas científicas. Essas limitações agravaram-se na segunda metade do século XX com o crescimento extraordinário da pesquisa científica e do número de títulos de periódicos e quantidade de artigos publicados. Esta mesma estrutura de comunicação $e$ as limitações a ela inerentes, que impedem o acesso universal às publicações, repetem-se de modo similar nos processos de publicação $e$ disseminação de monografias, livros, teses, anais de congresso, documentos governamentais (particularmente dos ministérios e secretarias de saúde), legislação etc, descontadas as características de cada um destes tipos de literatura científica.

Dentre outras, destacam-se três limitações que são intrínsecas à estrutura tradicional da comunicação científica:

a a demora existente entre o momento que os autores registram os resultados da pesquisa nos manuscritos e a sua disponibilidade para os usuários, por meio dos índices bibliográficos e das coleções das bibliotecas. A duração completa deste ciclo leva meses, às vezes anos;

b a impossibilidade real do acesso universal aos periódicos científicos, visto que as bibliotecas se tornaram incapazes de operar o desenvolvimento de suas coleções locais em correspondência com o crescente número de publicações, devido às limitações de infraestrutura de espaço físico, recursos humanos e, em especial, financeiros. Estas últimas têm relevância especial porque os preços das assinaturas comercializadas pelas publicadoras privadas e sociedades científicas dos países desenvolvidos cresceram sistematicamente acima da inflação internacional. Além disso, a aquisição de cópias separadas de artigos nos serviços nacionais e internacionais, que poderia ser uma alternativa, implica também custos elevados e crescentes. Em resumo, somente uma parte da informação registrada no inicio é passível de fluir até o final do fluxo;

c o usuário precisa transladar-se até as instalações físicas da biblioteca para ter acesso a seus serviços $e$ a sua coleção. Esta limitação relativa à localização geográfica se faz mais sensível e inconveniente quanto maior a distância em que o usuário se encontra. A biblioteca, por sua vez, possui horário de funcionamento $e$ as mais concorridas podem exigir do usuário que enfrente filas e tempo de espera para receber atenção das bibliotecárias de referência e ter acesso às coleções locais.

Estas limitações, sentidas em todo o mundo, tornaram-se mais 
sensíveis nos países em desenvolvimento. Na grande maioria dos países da América Latina e Caribe, devido às crises econômicas persistentes nas últimas décadas, as aquisições de coleções de periódicos em moeda estrangeira diminuíram radicalmente, ao mesmo tempo que o número de usuários continuou a crescer (Sonis, 1980).

Na área da saúde, essas limitações foram superadas em parte com a criação da BIREME em 1967, resultado de um convênio entre a OPAS e o Governo do Brasil, por meio dos Ministérios da Saúde e Educação, Secretaria de Estado da Saúde de São Paulo e a então Escola Paulista de Medicina, hoje Universidade Federal de São Paulo, em cujo campus urbano em São Paulo esta se localiza. A BIREME coordena, desde então, o desenvolvimento de um programa de cooperação técnica em informação científica e técnica, envolvendo direta $e$ indiretamente a grande maioria das instituições acadêmicas, de pesquisa e de serviços em saúde dos países da América Latina e Caribe, com base no compartilhamento de recursos e no desenvolvimento de produtos e serviços comuns (Neghme, 1975).

Este programa de cooperação técnica avançou até o lançamento da Biblioteca Virtual em Saúde - BVS - em 1998, mediante três grandes paradigmas de gestão de informação científica e técnica: a biblioteca especializada clássica, o centro de informação com serviço de indexação e o sistema de informação.

\section{A biblioteca especializada na cooperação técnica}

Neste paradigma cabe à biblioteca a organização de coleções de publicações e a provisão de serviços para assegurar o acesso às fontes de informação $e$ conhecimento em saúde. Nessa condição foi criada a BIREME, como revela seu nome de nascimento - Biblioteca Regional de Medicina.

Em consonância com o estado da arte internacional e dos serviços de informação na época, derivados da estreita cooperação com a National Library of Medicine (NLM) dos Estados Unidos, a BIREME implantou três linhas de ação principais:

1 desenvolvimento de uma coleção centralizada de periódicos científicos em saúde em suporte papel, que em poucos anos tornou-se a mais importante da América Latina e Caribe. Esta coleção, complementada com a da NLM, permitia, em teoria, atender a praticamente todas as demandas de artigos científicos, mesmo com as inconveniências e demoras inerentes ao transporte físico das fotocópias descritas abaixo;

2 criação e operação de uma rede cooperativa de bibliotecas com vários objetivos específicos, incluindo: estender a cobertura geográfica de oferta de acesso à informação científica; aumentar a capacidade dos países em gestão de bibliotecas e serviços bibliográficos; e compartilhar as coleções de publicações, por meio de um serviço formalizado e cooperativo de localização e fornecimento de fotocópias de artigos;

3 implementação, em 1973, de serviço de pesquisa bibliográfica na base de dados MEDLINE, operado pela BIREME com o uso de computador de grande porte no então Instituto de Energia Atômica, localizado na Universidade de São Paulo, inicialmente por algumas horas por semana e posteriormente durante toda a semana. O serviço contava com terminais remotos nos estados de Minas Gerais, Bahia, Espírito Santo e Pernambuco conectados por teleprocessamento. Este foi provavelmente o primeiro serviço on line de consulta bibliográfica

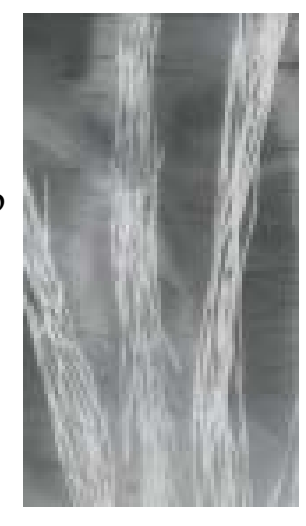


remota da América Latina e considerado na época modelo para outros países. A implementacão e operação do serviço teve a assistência da NLM que aportou a base de dados Medline, o sistema de pesquisa bibliográfica ELHILL e treinamento (NLM, 1974).

Este paradigma, embora enriquecendo ao máximo a função da biblioteca especializada clássica, privilegiava os usuários que tinham acesso físico à BIREME e às bibliotecas da rede com melhor desempenho, considerando a completeza das coleções locais e a qualidade dos serviços ao usuário. Durante muitos anos, nas décadas de 1970 e 1980, a BIREME e sua rede de bibliotecas atenderam às demandas de informação dos usuários de todos os países da região na seguinte seqüencia, difícil de imaginar-se atualmente:

i o usuário solicitava ao serviço de referência das bibliotecas da rede, em contato direto ou por correspondência, uma pesquisa bibliográfica sobre determinado tema. Os pedidos eram enviados por correio para o serviço de consulta bibliográfica da BIREME;

ii na BIREME, as bibliotecárias de referência realizavam as pesquisas bibliográficas, primeiro formulando-as em papel e depois as executando no computador. Os resultados, impressos em papel contínuo, eram entregues aos usuários locais ou enviados por correio à biblioteca onde o usuário fez o pedido original;

iii o usuário revisava as listas das referências bibliográficas e selecionava os artigos pertinentes e novamente dirigia-se à biblioteca para obter os textos. Quando o periódico não estava disponível localmente, o pedido era enviado por correio para a BIREME. Quase sempre as bibliotecas reuniam os pedidos para envios semanais;

iv a BIREME produzia fotocópias dos artigos dos periódicos presentes na sua coleção. Nos outros casos enviava os pedidos a outras bibliotecas da rede, à NLM ou à British Library, que, por sua vez, enviavam as cópias dos pedidos atendidos para a BIREME. A BIREME encaminhava, então, as cópias às bibliotecas dos países. Todos esses envios se faziam semanalmente de modo que se pode imaginar que um pedido ficava em processo e parado, em média, três dias nas bibliotecas, além do tempo de transporte por correio.

É fácil vislumbrar as dificuldades, complexidades e inconveniências inerentes a este fluxo de informação. Tipicamente, o ciclo acima demorava semanas e, não raro, meses. Entretanto, durante décadas atendeu à formação dos profissionais de saúde da região e às demandas de informação dos pesquisadores, profissionais, autoridades e gestores.

É importante notar que a estrutura subjacente deste paradigma persiste até os dias de hoje e continuará ainda por alguns anos enquanto houver necessidade de acesso remoto a cópias de artigos, sejam provenientes de coleções em papel ou eletrônicas. Entretanto, atualmente, os processamentos são realizados com a ajuda de sistemas computacionais e operados on line na Internet: a pesquisa on line está disponível na Internet diretamente para o usuário, assim como os pedidos de cópias de documentos. Desta maneira, reduzem-se drasticamente os tempos de localização e obtenção de artigos científicos e outros documentos.

O centro de informação e serviço de indexação na cooperação técnica Neste paradigma a BIREME agrega à biblioteca especializada a função de centro 
de informação e de serviço de indexação, dando início ao controle bibliográfico da literatura científica em saúde publicada nos países da América Latina e Caribe. Em 1979 foi lançado o Index Medicus Latino-Americano (IMLA), indexando cerca de 150 periódicos e complementando, assim, o Index Medicus publicado pela NLM, que até então indexava somente 44 títulos da América Latina e Caribe. Na apresentação do IMLA em seu primeiro número, o então Diretor da Organização Pan-Americana da Saúde (OPAS) justificava seu lançamento referindo-se às crescente atividades "médico-científicas" nos países da América Latina:

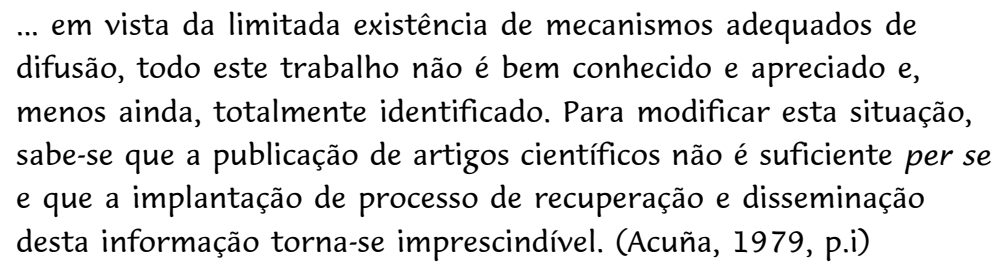

Esta decisão representa um reposicionamento da OPAS na gestão de serviços no fluxo de informação científica da América Latina e Caribe, com importância mundial: "A major step forward in the direction of complete bibliographic control of health literature produced in the Third World was the publication in 1979 of the first issue of the Index Medicus Latino Americano" (Ruff, 1980, p.165).

A BIREME deixa de servir apenas ao fluxo da literatura internacional e dá início a um longo processo de posicionamento da pesquisa científica publicada nacionalmente em patamares progressivamente mais altos de visibilidade $e$ acessibilidade. Este posicionamento conduz a BIREME a liderar posteriormente a criação e desenvolvimento da base de dados LILACS, e, a partir de 1997 a rede SciELO de coleções de periódicos eletrônicos on line na Internet.

No mesmo período, a BIREME ampliou o seu escopo temático de modo a cobrir todas as áreas de ciências da saúde, com ênfase em saúde pública, já com a perspectiva de promover o fortalecimento e a ampliação das fontes e fluxos de informação científica e técnica nos serviços nacionais de saúde.

Esta nova identidade informacional nas funções da BIREME é cunhada com a adoção de um novo nome em 1982: Centro Latino-Americano e do Caribe de Informação em Ciências da Saúde. A sigla BIREME, entretanto, permaneceu viva como uma lembrança persistente da biblioteca como origem.

\section{O sistema de informação regional na cooperação técnica}

A adoção deste paradigma é realizada pela BIREME com a descentralização para o âmbito dos países da América Latina e Caribe das funções de centro de informação e de serviço de indexação. Em outras palavras, os países, a partir das bibliotecas e centros de documentação ligados à rede da BIREME, passam a assumir a responsabilidade de atender às demandas de pesquisa bibliográfica dos usuários nacionais e de estabelecer o controle bibliográfico da literatura científica e técnica em saúde produzida nacionalmente.

Este paradigma é estabelecido nos últimos três anos da década de 1980 com a criação e consolidação do Sistema Latino-Americano e do Caribe de

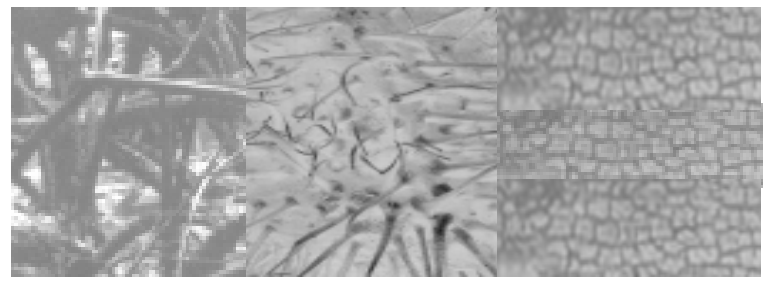


Informação em Ciências da Saúde, que pressupõe que cada país conte com um Centro Coordenador Nacional ( $\mathrm{CCN}$ ) e uma rede de Centros Cooperantes. A função de $\mathrm{CCN}$ era quase sempre ocupada pela principal biblioteca biomédica do país. O sistema incluía também centros regionais especializados em áreas temáticas como, por exemplo, meio ambiente, que contava com a Rede Panamericana de Informação e Documentação em Engenharia Sanitária $e$ Ciências do Ambiente (REPIDISCA), coordenada pelo Centro Pan-Americano de Engenharia Sanitária da OPAS (CEPIS/OPAS/OMS), localizado em Lima, Peru. Os centros de documentação das oficinas de países da OPAS sempre foram componentes destacados nesta estrutura.

A Figura 2 apresenta um esquema do sistema regional, destacando-se o fato de que a BIREME passa a ocupar na rede uma posição idêntica aos demais centros nacionais. O funcionamento articulado destes centros, em âmbito local, nacional e regional, produzindo de modo cooperativo produtos e serviços de informação, constituía a essência do sistema regional.

\section{Sistema Latino-Americano e do Caribe de Informação em Ciências da Saúde}

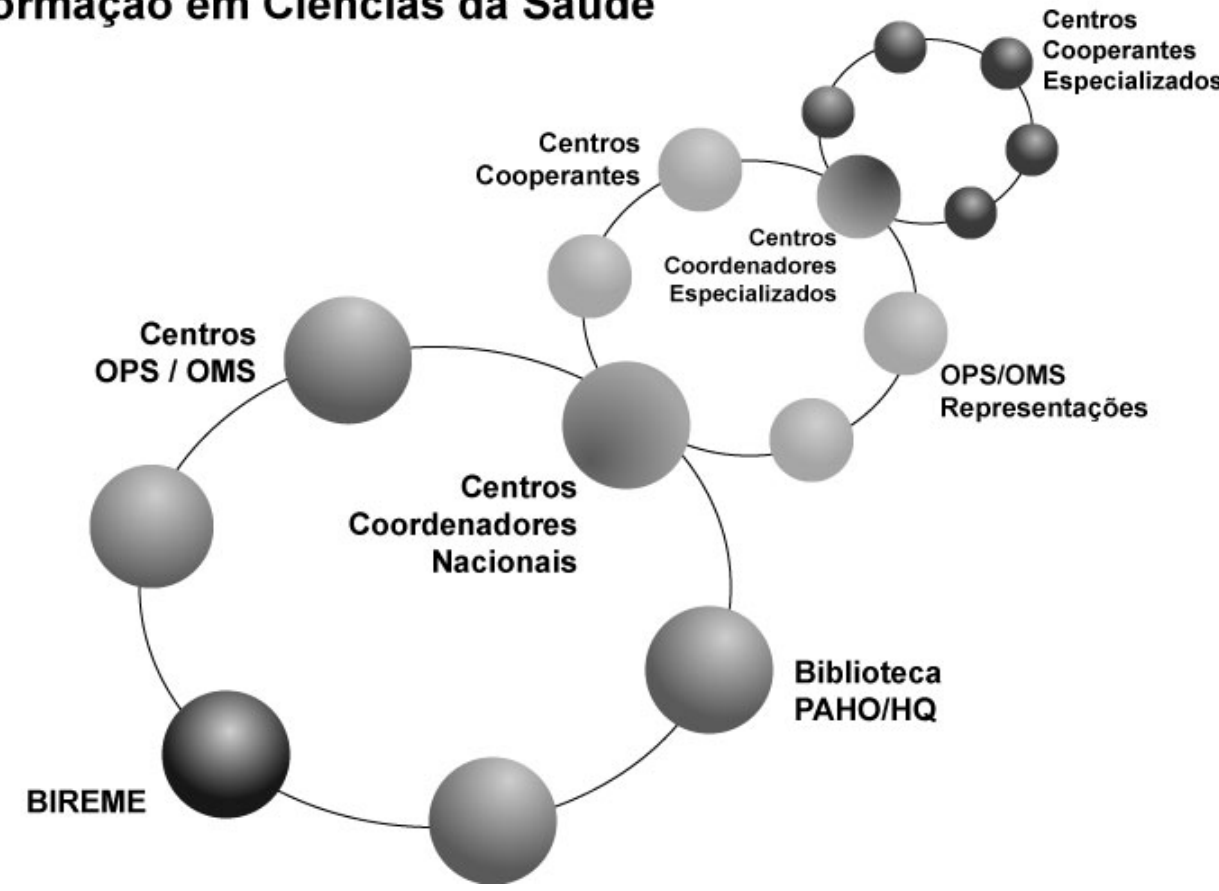

Figura 2. Esquema do Sistema de Sistemas de Informação: sistema regional, sistemas nacionais e sistemas especializados.

Três principais produtos e serviços passaram a ser operados de modo descentralizado nos centros cooperantes, com apoio de outros centros $e$ particularmente da BIREME: a base de dados LILACS, pesquisa bibliográfica em bases de dados (nacionais, regionais e internacionais) e o acesso cooperativo ao documento original. A função da BIREME passa a privilegiar a 
interoperabilidade entre os centros do sistema em torno a estes produtos $e$ serviços com a adoção, adaptação e desenvolvimento de um conjunto de padrões, metodologias e tecnologias de tratamento da informação, adaptado às condições locais e compatível internacionalmente.

O produto cooperativo mais importante do Sistema criado nesse novo paradigma foi a base de dados LILACS- Literatura Latino-Americana e do Caribe de Informação em Ciências da Saúde que, além da indexação dos periódicos científicos, inclui monografias, livros, documentos governamentais, teses de doutorado e anais de congressos. Esta base de dados é alimentada de modo descentralizado por centros nacionais, seguindo o esquema da Figura 2. Inicialmente a alimentação se dava por meio do preenchimento de formulários em papel, reunidos pelo Centro Coordenador Nacional e posteriormente enviados à BIREME, onde eram digitados para ingresso na base de dados LILACS.

Com o surgimento do computador de mesa e do software CDS/ISIS da Unesco, a BIREME promoveu oportunamente a descentralização completa da alimentação da base de dados nas redes nacionais, permitindo a criação de bases de dados nacionais com o objetivo de registro da memória da literatura científica, técnica e de divulgação em saúde produzida nos países. Os registros que obedeciam aos critérios de seleção LILACS eram gravados em disquetes nos centros cooperantes e enviados por correio à BIREME para ingresso na base de dados regional.

A LILACS, como produto principal da gestão das fontes e fluxos de informação científica e técnica, representa um avanço notável para a América Latina e Caribe, pois é baseada em padrões internacionais para a operação descentralizada em centenas de centros nos idiomas inglês, português $e$ espanhol. A descrição bibliográfica é baseada no padrão definido no Unisist Reference Manual sob a égide da Unesco (Dierickx E Hopkinson, 1981) e a indexação (descrição dos conteúdos por atribuição de palavras-chave ou descritores) é baseada na metodologia da National Library of Medicine utilizando o Medical Subject Headings (MeSH) como thesaurus. O MesH, traduzido para o português e espanhol e enriquecido com categorias de descritores orientados à Saúde Pública na América Latina e Caribe, denomina-se Descritores em Ciências da Saúde (DeCS) e é mantido rigorosamente atualizado pela BIREME, constituindo o vocabulário de indexação da BVS.

O segundo serviço de destaque era o de pesquisa bibliográfica, cuja descentralização efetiva ocorreu somente no final dos anos 1980, com o surgimento da tecnologia de cd-rom, acessível aos computadores de mesa por meio de leitores de disco compacto. A OPAS financiou um projeto histórico em 1988, que permitiu a distribuição de cerca de 110 computadores de mesa $e$ leitores de cd-rom para os principais centros cooperantes do Sistema, em todos os países da América Latina e na maioria da ilhas do Caribe. No Brasil o projeto contou com o apoio do CNPq para a distribuição adicional de cincoenta computadores de mesa e leitores de disco compacto (Castro et al., 1989).

Ao mesmo tempo, a BIREME capacitou-se na tecnologia de produção desses discos compactos, criando uma unidade de produção que gerava em disco magnético a matriz do disco compacto, enviada à fábrica de disco compacto para a produção da matriz e sua replicação nos Estados Unidos, nos primeiros anos, e posteriormente, no Brasil. Com o passar dos anos, a produção de discos compactos ficou mais acessível tecnológica e financeiramente. 
Com o domínio da tecnologia de cd-rom, a BIREME produziu os títulos LILACS/cd-rom e Medline/cd-rom, que, pela primeira vez na história, permitiu aos países da América Latina e Caribe terem acesso local à literatura científica relevante internacional, regional e nacional. O disco LILACS/cd-rom publicava, além da LILACS, um conjunto de outras bases de dados bibliográficas, incluindo os catálogos das coleções de publicações da OPAS e da OMS. De 1988 a 2005 foram publicadas cincoenta edições de LILACS-cd-rom. A publicação do Medline/ cd-rom pela BIREME iniciou-se em 1995 e continuou com atualizações mensais por sete anos, até 2001, quando foi interrompida.

A partir de 1985, a BIREME passou a operar, on line, um serviço de consulta às bases de dados bibliográficas LILACS e Medline, utilizando o serviço RENPAC (Rede Nacional de Pacotes), em protocolo X-25, oferecido pela então empresa pública nacional de telecomunicação (Embratel). Este serviço tinha alcance restrito ao Brasil, devido ao alto custo da conexão internacional. O cdrom, com todas suas limitações, era, ainda por alguns anos, o meio que permitia acesso mais amplo. No entanto, esta experiência pioneira serviço público on line foi essencial para promover o acesso para as instituições brasileiras conectadas na RENPAC e principalmente para desenvolver a capacidade da BIREME na gestão e operação de serviços on line, que se tornaram prioritários com o surgimento e a consolidação da Internet.

Em 1988 foi disponibilizado, pela primeira vez, serviço de acesso on line através da Internet, utilizando inicialmente o protocolo telnet. Para isso, a BIREME utilizava o software MINISIS, desenvolvido pelo IDRC do Canadá, substituído, em 1995, por uma interface de recuperação própria desenvolvida com o software CISIS. O serviço RENPAC foi interrompido em 1998. A partir de 1988, houve um avanço sistemático no uso da Internet, com a operação do primeiro site da BIREME em 1994.

$O$ avanço da Internet em todo o mundo e, em particular, seu uso progressivo na operação de fontes e fluxos de informação na BIREME, contribuíram decisivamente para o lançamento da BVS em 1998, como o novo modelo de cooperação técnica da BIREME. Na época, o site da BIREME recebia dez mil visitantes por mês, número que nunca mais parou de crescer, chegando em 2005 com uma média de mais de um milhão e quinhentos mil visitantes por mês.

O terceiro serviço integrado ao funcionamento do Sistema Regional foi o acesso cooperativo ao documento original, que progressivamente passa a ser realizado como o apoio de sistemas computacionais, especialmente no que se refere à gestão central dos pedidos, realizada pela BIREME. Este sistema, denominado na BVS de Serviço Cooperativo de Acesso ao Documento (SCAD) opera ativamente até hoje com uma média diária de mais de mil pedidos de cópias por dia (em 2005), atendidos cooperativamente por uma rede de mais de trezentas bibliotecas cooperantes. Ao iniciarem-se as estatísticas do serviço de fotocópias, em 1969, o número total de pedidos foi de 12.800, chegando a $325.000 \mathrm{em} 2004$.

\section{A reestruturação da comunicação científica e a cooperação técnica} Nos três paradigmas de cooperação técnica em informação científica e técnica descritos, houve um progresso sistemático na capacidade de gestão de informação científica e técnica das instituições acadêmicas e de serviços de saúde dos países da América Latina e Caribe, acompanhando o estado da arte 
internacional, com um atraso em média não maior de um ano nas instâncias mais avançadas. Com relação aos aspectos tecnológicos, essenciais na comunicação científica, a opção prioritária da BIREME por soluções contemporâneas e de baixo custo, incluindo computadores e softwares $e$ aplicações de domínio público, foi e tem sido decisiva para aumentar progressiva e sustentavelmente a inclusão digital das instâncias relacionadas ao fluxo de informação científica, especialmente bibliotecas, centros de documentação, editores e gestores de bases de dados.

Embora a consolidação de cada novo paradigma tenha representado um avanço notável, não houve qualquer ruptura radical com substituição completa de um modus operandi por outro. Ao contrário, houve um processo gradual de absorção dos paradigmas anteriores, que se deu em tempos e intensidades diferentes nos diferentes países e internamente nos países. Embora o uso intensivo de tecnologias de informação tenha tornado muito mais eficiente a operação das fontes e dos fluxos de informação, a estrutura clássica da comunicação científica, como esquematizado na Figura 1, permaneceu inalterada nos três paradigmas. Na essência, o modo de produção do fluxo de informação científica não se modificou.

Nesta estrutura clássica, além das restrições mencionadas anteriormente $e$ relacionadas com a impossibilidade do acesso universal às fontes de informação e com a demora na condução dos registros e fluxos de informação entre as instâncias físicas, o objetivo essencial do ato de publicar se frustra devido à pouca visibilidade e quase nenhuma acessibilidade provida aos periódicos publicados em suporte papel na América Latina e Caribe, situação que ficou conhecida como "ciência perdida do terceiro mundo" (Gibbs, 1995).

A publicação do IMLA, a partir de 1979 , representou o primeiro produto com o objetivo de estabelecer o controle bibliográfico da literatura científica publicada nos países e promover a sua visibilidade. A criação e operação descentralizada da base de dados LILACS, a partir de 1985, a sua publicação em cd-rom, a partir de 1988, nesta data também disponibilizada no serviço on line de pesquisa bibliográfica da BIREME na Internet, representam avanços notáveis no sentido de promover visibilidade aos resultados da pesquisa científica em saúde na América Latina e Caribe publicada nos periódicos nacionais e regionais.

Entretanto, permanecia a limitação de acesso aos textos originais porque, ao realizar uma pesquisa bibliográfica na base de dados LILACS, desde qualquer lugar via Internet, a obtenção dos textos dos artigos selecionados dependia da presença do periódico na biblioteca local ou de pedido de fotocópia ao serviço SCAD. Este serviço, embora eficiente em sua operação na Internet, representa uma barreira aos usuários, pois demanda a inscrição no serviço com a inconveniência dos sistemas de cobrança.

Esta limitação de acesso ao texto completo passa a ser progressivamente superada com o aparecimento da publicação eletrônica on line na Internet, cujo desenvolvimento mais notável na América Latina e Caribe é representado pela rede SciELO de coleções nacionais e temáticas de periódicos de qualidade da América Latina, Caribe, Espanha e Portugal. O objetivo do projeto SciELO Scientific Electronic Library Online, iniciado em 1997 como produto da cooperação entre a BIREME e a Fapesp, foi justamente contribuir para aumentar a visibilidade $e$ a acessibilidade dos periódicos. Para tanto, a metodologia SCiELO optou pela publicação em acesso aberto de coleções de 


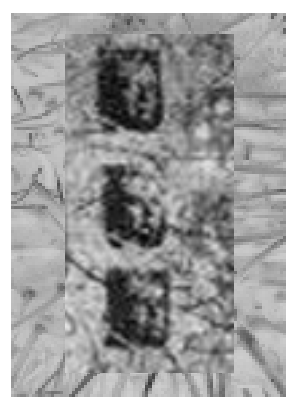

periódicos selecionados por critérios de qualidade, com aumento constante dos enlaces a outras fontes de informação, construindo aos poucos um índice bibliográfico de referência de periódicos de qualidade, que inclui a publicação on line de estatísticas e indicadores bibliométricos de uso e citação. Pela primeira vez se abriu a possibilidade real da produção científica produzida nos periódicos nacionais possuir indicadores numéricos atualizados para sua avaliação, complementando, assim, os indicadores internacionais (Packer et al., 1998; Meneghini, 2002).

A questão de visibilidade e acessibilidade dos periódicos da América Latina $e$ Caribe passa a ter na SciELO, finalmente, uma solução efetiva. É importante destacar que esta questão aplica-se também aos outros tipos de literatura científica e técnica, incluindo particularmente os documentos governamentais, das agências de cooperação internacional, as teses, os anais de congressos etc.

O fluxo de informação que se inicia com essas publicações em suporte papel não tem sustentabilidade para chegar a todos os usuários com acesso universal. Esta situação afeta especialmente as fontes e fluxos de informação que são necessários para subsidiar a gestão e operação dos sistemas e serviços de saúde. Assim, publicação eletrônica on line passa a ser também obrigatória como solução para visibilidade e acessibilidade para todos os tipos de documentos incluídos nos critérios de seleção da LILACS. Em conseqüência, nos anos 1990 a Internet como meio de comunicação científica e técnica representa o novo desafio programático, organizacional e tecnológico para a cooperação técnica em informação científica e técnica, liderada pela BIREME.

Com a SciELO e a publicação eletrônica em geral, a cooperação técnica promovida pela BIREME começa a expandir-se nas instâncias do fluxo da comunicação científica, convergindo, por um lado, com os editores de periódicos e produtores em geral, e, por outro, com os usuários que passam a operar e interagir diretamente com os produtos e serviços de informação. Esta expansão, viabilizada pela Internet, abre as fronteiras e condições para a consolidação da BVS como o novo paradigma de cooperação técnica.

O uso da Internet como tecnologia e meio de produção do fluxo informação da comunicação científica e técnica tem evoluído de uma conformação inicial, em que predominou o trabalho isolado dos atores em cada uma das instâncias esquematizadas na Figura 1, para uma nova conformação, na qual predomina a convergência das ações no espaço virtual criado pela Internet. Na Internet, o fluxo da informação é conduzido por arquivos e mensagens digitais, eliminando-se, portanto, a necessidade do transporte físico de documentos entre as instâncias da comunicação científica clássica em suporte papel. Estes arquivos são passíveis de serem criados, modificados $e$ acessados universalmente desde qualquer lugar, eliminando-se a distância física no processo de comunicação entre os atores nos diferentes eventos da comunicação científica.

Em conseqüência, com a Internet, a comunicação científica sofre aceleradamente uma restruturação radical, caracterizada pela convergência do trabalho dos atores no espaço virtual da Internet, disponibilidade dos conteúdos na Internet para acesso universal e um alto grau de simultaneidade entre os eventos. Em resumo, emerge uma nova estrutura de comunicação científica e técnica, na qual os eventos de escrever e submeter o manuscrito, sua revisão por pares e, quando aprovado, sua edição, publicação, indexação $e$ acesso ocorrem todos nesse mesmo espaço, com um alto grau de 
simultaneidade dos eventos. Ademais, a nova estrutura (esquematizada na Figura 3) possibilita que todas as publicações sejam universalmente acessíveis.

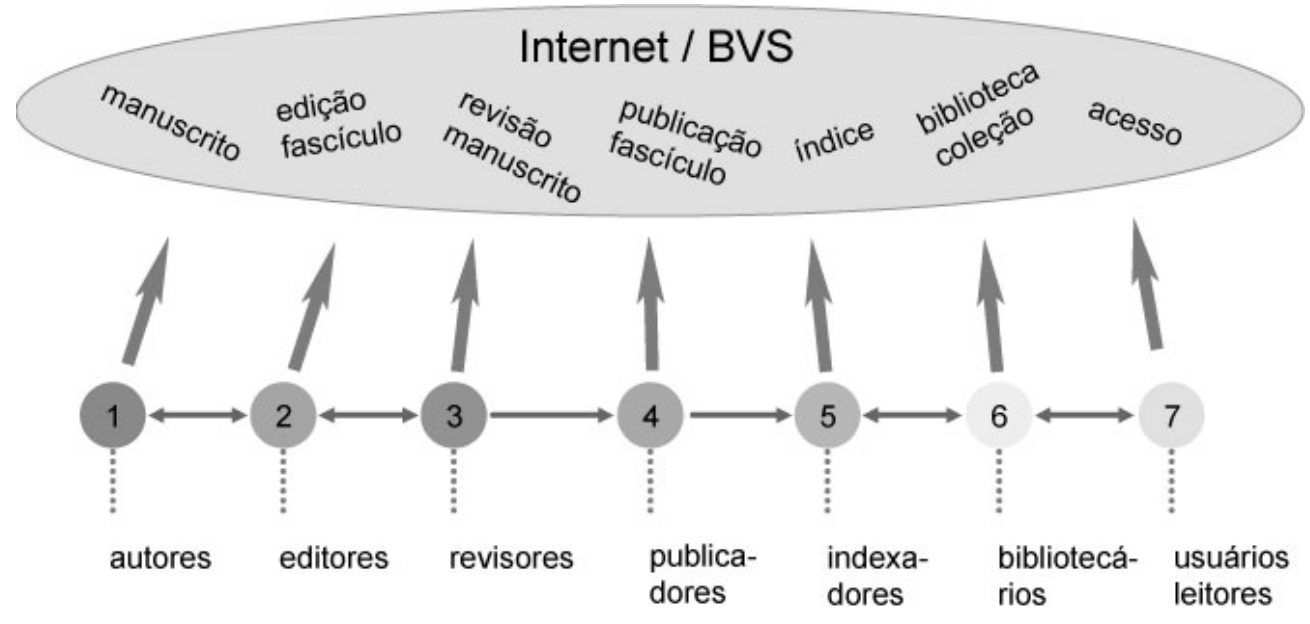

Figura 3. Restruturação da comunicação científica na internet. Os eventos, atores e instâncias convergem para o ciber-espaço com alta simultaneidade de eventos

A restruturação da comunicação científica vem impactando processos, atores, instâncias e eventos. Além da dimensão inovadora que a Internet aporta como tecnologia de meio de publicação, surge a dimensão de caráter político que preconiza o conhecimento científico como bem público, indispensável para o desenvolvimento social e econômico, particularmente para contribuir a superar a pobreza. Nesse sentido, estão se fortalecendo cada vez mais os movimento de open access e dos repositórios pessoais, institucionais e temáticos. Nessas modalidades, o artigo será disponibilizado para livre acesso tão logo seja publicado em algum periódico ou depois de um embargo de alguns meses para auto-arquivamento em algum repositório (National Academies, 2004).

Ao comparar-se a estrutura da comunicação científica clássica em papel, como esquematizada na Figura 1, com a nova estrutura da Internet como meio de publicação, segundo esquema da Figura 3, salta à vista que as limitações para o acesso universal ao conhecimento científico estariam em princípio superadas tecnologicamente. Em resumo, a comunicação científica na nova estrutura apresenta as seguintes características:

a o tempo entre a submissão do trabalho $e$ a disponibilidade para acesso pelos usuários é minimizado;

$\mathrm{b}$ todos os trabalhos publicados são passíveis de acesso universal, a qualquer hora, independentemente do lugar em que se encontra o usuário;

$c$ a visibilidade e acessibilidade podem ser maximizadas.

A promoção da convergência dos atores da comunicação científica e técnica da América Latina e Caribe para operar em rede na Internet, criar um espaço cooperativo de gestão e operação das fontes e fluxos de informação e, assim, avançar rumo ao acesso eqüitativo ao conhecimento e à informação científica, técnica e factual em saúde, conformam o novo paradigma de cooperação técnica entre as instituições de pesquisa, ensino e atenção à saúde da América Latina e Caribe, sob a liderança da BIREME/OPAS/OMS. 


\section{O paradigma da Biblioteca Virtual em Saúde}

A característica principal que rege a formulação da BVS está na adoção plena do paradigma de informação e comunicação da Internet, no qual a gestão e a operação das fontes e fluxos de informação passam a ser realizadas em formato digital em rede online, diretamente pelos seus diferentes atores. A Internet passa a ser o meio de produção e operação da comunicação científica, superando as limitações causadas pela distância física entre os atores, o transporte físico de documentos entre eles, bem como as restrições de horário de funcionamento das instituições, particularmente das bibliotecas.

Com a Internet como meio, os registros que conduzem os fluxos de informação e de trabalho dos diferentes atores podem ser compartilhados ao mesmo tempo em que são realizados. Esta possibilidade de compartilhar os registros resultantes das ações realizadas por atores localizados fisicamente nos mais diferentes lugares gera a percepção e a sensação de um espaço comum e convergente de trabalho que se atualiza continuamente, isto é, um espaço virtual.

Nos paradigmas anteriores, a cooperação técnica liderada pela BIREME envolvia diretamente os atores $e$ as instâncias de indexação, biblioteca e usuários. Com a BVS, a rede amplia-se quase que naturalmente, incluindo também a participação dos editores e da publicação eletrônica. Este movimento envolve não somente os fluxos de informação e de trabalho em torno aos periódicos científicos, mas abarca também os diferentes tipos de comunicação e documentação científica e técnica, assim como informação factual e multimídias. Os ciclos de informação persistentes são passíveis de funcionar além dos contextos acadêmicos.

Esta expansão é uma mudança transcendental, pois a BVS passa ser ao mesmo tempo produto e produtora na nova estrutura de comunicação científica em saúde na América Latina e Caribe. Daí ser uma das características-chave projetadas no seu desenvolvimento constituir-se em espaço de referência para a informação $e$ conhecimento em saúde, com controle de qualidade.

Numa visão idealizada a BVS é um tecido virtual na Internet, onipresente e disponível todo o tempo para interação, no qual é possível colocar e retirar conteúdos, em um contexto orientado ao acesso eqüitativo à informação em que todos os atores envolvidos estão dotados de tecnologias para acessar e publicar.

É importante reforçar que esse avanço conceitual na comunicação científica $e$ técnica $e$ a possibilidade de colocá-lo em prática na cooperação técnica se torna possível e é viabilizado pelas tecnologias de informação que envolvem a Internet, extensões do nosso sistema físico e nervoso para aumentar a força e a velocidade (McLuhan, 1974). Embora aumentem nossa capacidade e sejam em si mesmas uma força inovadora, não deixam de ser meio.

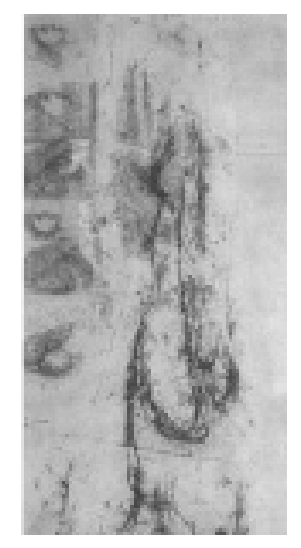

O estado das técnicas influi efetivamente sobre a topologia da megarrede cognitiva, sobre o tipo de operações que nela são executadas, os modos de associação que nela se desdobram, as velocidades de transformação $e$ de circulação das representações que dão ritmo a sua perpétua metamorfose. A situação técnica inclina, pesa, pode mesmo interditar. Mas não dita. (Levy, 1993, p.186)

A tecnologia na BVS visa ao desenvolvimento da saúde individual e coletiva, isto é, o papel da informática e das técnicas de comunicação com base digital não seria substituir o homem', nem aproximar-se de uma hipotética 
PACKER, A. L.

inteligência artificial', mas promover a construção de coletivos inteligentes, nos quais as potencialidades sociais e cognitivas de cada um poderão desenvolver-se e ampliar-se de maneira recíproca. (Levy, 1998, p.25)

O paradigma da BVS conforma uma inovação importante, que é a operação de redes em duas dimensões. Na primeira delas, têm-se as redes de instituições $e$ indivíduos que operam os fluxos de informação e de trabalho, isto é, os atores relacionados com a produção, a intermediação e a exploração das fontes de informação. Na segunda dimensão, têm-se as redes de fontes de informação propriamente ditas, que são organizadas e indexadas na BVS. Essas incluem qualquer recurso que responda a uma nessidade de informação, produtos, serviços e eventos.

Esta conformação da BVS é explicitada para o campo operacional por um modelo de gestão e um marco de trabalho, tendo por um lado o ser humano $e$ por outro o resultado da sua ação registrado, armazenado, escrito $e$ comunicado na BVS, que funciona como memória externa, de caráter coletivo. Nesse sentido, a BVS constitui espaço de expressão e ação da inteligência coletiva.

O modelo está orientado ao aperfeiçoamento e crescimento contínuo de ambas as redes e dos seus constituintes. Por um lado, visa desenvolver a capacidade dos produtores, intermediários e usuários no tratamento de fontes de informação em formato digital em rede. Por outro lado, o modelo pretende aumentar a quantidade e aperfeiçoar a qualidade dos conteúdos das fontes de informação e seu funcionamento efetivo na resposta a demandas de informação nos diferentes contextos. A cooperação técnica entre os países $e$ entre a suas instituições e usuários, com apoio internacional da BIREME/OPAS/ OMS, é naturalmente o meio e a estratégia requerida para aperfeiçoar o modelo conceitual e operacional, fortalecendo e ampliando nestas áreas estratégicas as capacidades dos países da região. A BVS tem expansão ilimitada dirigida a maximizar a inclusão digital e informacional.

O avanço sustentável da operação da BVS é baseado na experiência consolidada das bibliotecas e instituições de saúde da América Latina e Cariba no trabalho em redes colaborativas de informação, com um consenso crescente que a operação em rede fortalece cada um dos seus componentes individualmente e na sua interoperação com os demais: que é melhor agir em rede que atuar isoladamente, $e$ as evidências nesse sentido são dadas pelos valores crescentes dos indicadores de visibilidade, acessibilidade e impacto das instâncias, atores e suas fontes de informação na BVS. Por exemplo, um periódico científico indexado na LILACS e publicado na coleção SciELO tem mais impacto e credibilidade que publicado isoladamente na Internet. $\mathrm{O}$ mesmo acontece com um curriculum de investigador na Plataforma Lattes com links com outras fontes de informação. Esta interoperação, quando maximizada, lembra um fenômeno da ressonância por meio dos fluxo crescentes de informação entre os nós das redes. Para tanto, a BVS é necessariamente construída como um espaço coletivo e de domínio público com gerenciamento e lideranças compartilhadas.

A gestão da rede de produtores, intermediários e usuários da BVS Como espaço de domínio público, a BVS não tem dono e a sua gestão deve ser 
compartilhada e realizada em rede. Em particular, a função da cooperação técnica entre as instituições, promovida e coordenada pela OPAS/OMS, por meio da BIREME, é regida pelos seguintes princípios: busca da eqüidade de acesso à informação em saúde; promoção de alianças e consórcios para maximizar o uso compartilhado de recursos; promoção do trabalho cooperativo e do intercâmbio de informação, experiências e conhecimento; desenvolvimento e operação em rede com descentralização em todos os níveis geográficos, temáticos $e$ instituicionais; desenvolvimento baseado nas condições locais; estabelecimento e aplicação de mecanismos integrados de avaliação e controle de qualidade.

Os princípios acima regem a cooperação técnica entre instuições e em nada interferem na sua gestão e operação interna e tampouco em suas políticas, procedimentos e idiossincrasias em gestão de informação. Estão orientados para assegurar o desenvolvimento cooperativo de produtos, serviços e eventos de informação que transdendem a instituição embora com a sua inserção na rede de divisão do trabalho e compartilhamento de recursos. Entretanto, como se analisará em seguida, a adoção do novo paradigma de informação $e$ comunicação internamente implica em mudanças significativas no modus operandi interno das organizações.

Como parte da gestão do desenvolvimento da BVS, a BIREME promove a cada dois anos uma reunião regional de coordenação, que funciona como fórum e oficina de trabalho para avaliação, intercâmbio de experiências $e$ elaboração de recomendações futuras, particularmente para os dois anos seguintes. Estas reuniões presenciais fortalecem a apropriação da BVS por parte das instituições nacionais como espaço coletivo de cooperação e contribuem para o aperfeiçoamento do modelo conceitual e operacional de gestão em rede de fontes e fluxos de informação. Em especial, contribuem para aperfeiçoar $e$ fortalecer as funções e mecanismos da cooperação técnica, que se traduzem em normas, guias e metodologias. O Guia da BVS (BIREME, 2001), que descreve o modelo da BVS, é atualizado periodicamente em função dessas reuniões de coordenação e avaliação.

A BIREME é responsável também pela coordenação e operação direta das fontes de informação regionais que envolvem conteúdos dos países da América Latina e Caribe e interação entre elas, como são por exemplo a LILACS, SciELO, SCAD etc. Responsabiliza-se, também, pela operação das fontes internacionais essenciais, como o Medline e a Cochrane.

Ainda no âmbito regional, os programas de cooperação técnica da OPAS em áreas temáticas têm promovido a inserção progressiva das suas redes na BVS, como por exemplo, meio ambiente, adolescência, pesquisa científica etc. As áreas temáticas são gerenciadas no espaço da BVS como redes específicas, considerando as fortalezas e afinidades existentes entre instituições, pesquisadores e profissionais na gestão das fontes e fluxos de informação. Assim, no espaço da BVS tem-se consolidado a denominação específica de "BVS temáticas" como, por exemplo, BVS Saúde Mental.

A BIREME promove também a intermediação com instituições, redes, sistemas e iniciativas internacionais de modo a fortalecer e ampliar os vínculos da América Latina e Caribe com os paises do norte assim como com outras regiões em desenvolvimento.

Como centro especializado da OPAS/OMS, a BIREME se posiciona naturalmente na agenda internacional de cooperação técnica, de forma que as 
suas ações são realinhadas periodicamente às prioridades da OPAS/OMS e dos programas internacionais e nacionais de desenvolvimento, como ocorre atualmente com Objetivos de Desenvolvimento do Milênio das Nações Unidas e o desenvolvimento da sociedada da informação. A BVS é também instância integral da cooperação técnica internacional. O espaço da BVS serve para a convergência das iniciativas, fontes e fluxos de informação internacional. Desta forma, a BVS incorpora a indexação $e$ o acesso à todas a documentação técnicocientífica produzida pela OPAS e OMS e, seletivamente, dos outros organismos internacionais.

A BIREME representa a América Latina e Caribe na rede SHARED, que está estruturada por instâncias regionais, incluindo também a Africa, Ásia, Europa e Europa do Leste.

Outra dimensão de intermediação internacional é realizada por meio do Congreso Regional de Informação em Ciências da Saúde (CRICS), que tem lugar a cada dois anos com o objetivo de socializar o estado da arte internacional da comunicação científica e técnica internacional.

Assim, as funções de coordenação regional da BVS pela BIREME incluem, entre outras, as seguintes atribuições principais: promover e disseminar a BVS entre autoridades, gestores, pesquisadores, profissionais e público em geral; operar o site regional multilíngüe da BVS www.bvsaude.org, que funciona como um portal com interface de acesso e navegação às fontes de informação regionais e a toda rede distribuída de fontes de informação, assim como à fontes internacionais; promover a inter-operação das fontes de informação da BVS entre si e também com fontes externas; promover o intercâmbio de informação, experiência e conhecimento entre os produtores, intermediários $e$ usuários de fontes e fluxos de informação da BVS no âmbito nacional, regional $e$ internacional; efetivar cooperação técnica para o desenvolvimento da capacidade das instituições nacionais na gestão e operação da BVS, em sintonia com o estado da arte internacional em gestão de informação e conhecimento; coordenar em âmbito regional o funcionamenteo das redes de instituições produtoras, intermediárias e usuárias de fontes de informação na BVS; avaliar periodicamente o desenvolvimento da BVS com o objetivo de certificar as instâncias nacionais, temáticas e institucionais que cumprem os critérios de qualidade para inclusão na rede da BVS; coordenar o desenvolvimento do modelo conceitual da BVS; coordenar o desenvolvimento de metodologias $e$ tecnologias para a gestão e operação das redes de produtores, intermediários $e$ usuários, assim como das redes de fontes e fluxos de informação da BVS.

No âmbito geográfico nacional, o modelo de cooperação técnica atribui a cada país a responsabilidade por organizar as redes nacionais de instituições $e$ sua operação no espaço da BVS, como meio essencial para promover e assegurar a visibilidade e acessibilidade à informação e conhecimento em saúde gerado nacional e internacionalmente. As redes dos sistemas nacionais de informação que operavam bem antes do paradigama da Internet vêm se integrando progressivamente ao modelo da BVS, o que tem significado um avanço notável rumo a inclusão digital $e$ informacional dos atores $e$ instâncias relacionadas com a comunicação científica e técnica em saúde. A BVS significa a possibilidade concreta de promover e fortalecer a inclusão das instituições e indivíduos na gestão em rede das suas fontes e fluxos de informação.

A promoção e coordenação da BVS nos países é feita por uma ou mais instituições, seguindo os mesmos principíos e funções orientadores da ação da 


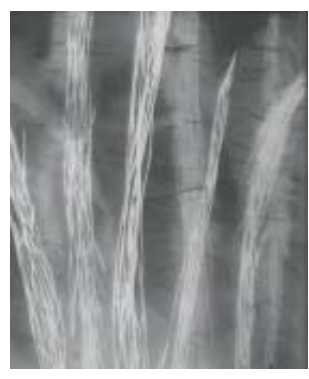

BIREME no âmbito regional. No contexto nacional da BVS, assim como nas áreas temáticas, a gestão compartilhada das redes deve ser continuamente aperfeiçoada $e$ as experiências positivas da BIREME e das instituições nacionais são socializadas e compartilhadas.

$\mathrm{O}$ desenvolvimento da BVS baseada em redes nacionais e regionais tem avançado sistematicamente, medido pela participação das instituições em atividades via Internet relacionadas com produção, intermediação ou uso de informação e conhecimento em saúde. Este avanço inclui o fato que a cooperação técnica expande-se para todos os atores do processo, além das bibliotecas e centros de informação, que formaram as redes nos paradigmas anteriores. Entretanto, as bibibliotecas e centros de documentação permanecem na coluna vertebral da operação da BVS.

Com a operação das redes na Internet, dois avanços são notáveis. Por um lado, os usuários foram dotados com a possibilidade e capacidade de acesso direto às fontes de informação para consultas e navegação. Esta desintermediação resolveu de vez as barreiras que enfrentavam no acesso às fontes de informação e tem resultado em um aumento extraordinário no uso da BVS. O acesso ao espaço virtual das coleções de fontes de informação superou as imposibilidades ou invonveniencias que eram impostas pela geografia das bibliotecas de coleções em suporte papel. Por outro lado, as instituições dos sistemas de saúde, pesquisa e ensino, passaram a operar em rede na Internet as suas fontes de informação principalmente por meio das suas bibliotecas e centros de documentação. Daí que uma das primeiras linhas de ação promovidas e implantadas no plano para a posta em marcha da BVS foi justamente o realinhamento para a Internet dos produtos e serviços de informação. Outra linha de ação que favorece a desintermediação e portanto a inclusão informacional dos usuários das instituições consiste na sua capacitação no uso direto e interativo das fontes de informação da BVS. Novamente, as bibliotecas e centros de documentação são chamadas frequentemente para promover e conduzir treinamento na exploração das fontes de informação (BIREME, 1998).

Mas, por muito tempo, a inserção das instituições consistirá na operação em rede pública da BVS, sem necessariamente introduzir este paradigma no seu contexto interior. De fato, tal processo de adoção do modelo da BVS nos contextos interiores das instituições, implica o envolvimento de todo o seu pessoal na operação das suas fontes e fluxos de informação. E revela-se ser uma força inovadora que requer mudanças sensíveis no sentido de um modus operandi informado, no qual predomine a circulação de informação, experiências e conhecimento e se conforme em um abiente aprendiz. Como realizar este movimento? Uma linha de ação é fortalecer a interação entre o contexto local do trabalho e gestão de informação com o espaço público da BVS, em que ambos se transformam $e$ as instituições aprendem e adoptam o modelo para seu interior. Os dois principais desafios que as organização enfrentam são, por um lado, a incorporação da maioria do seu pessoal em ambientes informados e, por outro lado, a construção coletiva da BVS, que prevê a interação da fontes locais de informação com a rede de fontes nacionais, regionais e internacionais. O primeiro desafio requer que a gestão dos ambientes promova a explicitação, o intercâmbio e registro do conhecimento próprio dos funcionários, individual e coletivamente, com vistas a sua organização em fontes de informação para preservar e facilitar o seu uso no 
presente e no futuro. O segundo desafio tem como solução a médio e longo prazo a operação local das fontes e fluxos de informação em um continuum com o espaço comum da BVS e da Internet em geral. Uma fase intermediária acontece com a indexação das fontes operadas isoladamente pelas instituições no espaço da BVS.

A superação de ambos desafios reside em aperfeiçoar o funcionamento dos ambientes institucionais, maximizando a troca, a comunicação, o compartilhamento de informação e conhecimento entre as pessoas. Este tipo de ambiente contribui a minimizar as decisões e conduções autocráticas ou baseadas em conhecimento e práticas obsoletas ou alienadas. A gestão é a do poder e liderança compartilhadas.

Em qualquer dos contextos anteriores, internacional, regional, nacional, local, institucional, a adoção, o desenvolvimento e a gestão compartilhada da BVS se faz necessáriamente por meio da articulação constante entre os representantes das principais instituições de saúde. No caso das instâncias nacionais incluem-se, como essenciais, o Ministério da Saúde e instituições gestoras do sistema nacional de saúde, instituições acadêmicas de ensino e pesquisa, instituições de apoio à pesquisa e à comunicação científica, associações profissionais, sociedades científicas, bibliotecas, editoras etc. No caso das instâncias temáticas, a articulação é feita em geral a partir das redes ou comunidades temáticas já existentes, de modo que a BVS contribua com o seu espaço e momentum para a gestão de suas fontes e fluxos de informação.

O estabelecimento e a operação de uma instância na BVS, regional, nacional, temática ou institucional, são conduzidos por processos que incluem a articulação permanente entre as instituições participantes, uma coordenação formada por uma instituição, um comitê consultivo e comitês técnicos, a operação de uma comunidade virtual em rede e um plano de implantação. Nem de longe se trata de uma operação trivial. Ao contrário, requer de gestão e engenharia de processos que se tornam mais complexos por serem compartilhados e realizados em rede. A BVS contribui para a aprendizagem $e$ formação de capacidades nesse sentido.

\section{A gestão das redes de fontes e fluxos de informação na BVS}

A segunda dimensão das redes operadas segundo o modelo da Biblioteca Virtual em Saúde - BVS - está relacionada com a condução da informação, literalmente do autor para o leitor, intermediada por meios de registro digital na Internet. A BVS funciona como meio para a informação gerada, intermediada e recebida por diferentes instâncias e atores, em diferentes localidades e datas ou momentos. Trata-se de meio assíncrono, nos moldes da biblioteca tradicional e também de modo síncrono viabilizado pela Internet. Nesses dois moldes a BVS registra, armazena, indexa, preserva e disponibiliza informação por meio de produtos, serviços e eventos denominados genericamente de fontes de informação. Quando essas fontes são acessadas, em qualquer estágio do seu desenvolvimento, a informação é comunicada para os usuários ou para outras fontes de informação, num processo que produz $e$ mantém os fluxos de informação.

O objetivo da gestão das fontes e fluxos de informação na BVS é maximizar, por um lado, a sua coleta, registro e organização, e, por outro, o uso da informação nos processos de decisão e nas atividades relacionadas com a saúde coletiva e individual. Então, como programa de cooperação técnica, a BVS

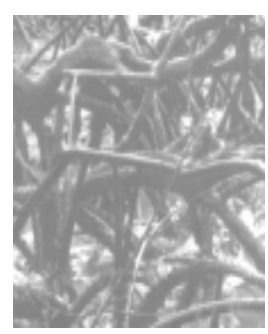


deverá estimular e contribuir para que a informação e o conhecimento de distintas naturezas venham a permear os diferentes contextos nos sistemas nacionais de pesquisa, educação $e$ atenção à saúde. Os contextos devem ter seus fluxos de informação continuamente retroalimentados e enriquecidos com informação de outros contextos, de forma a aumentar sua capacidade para tratar temas ou problemas, respondendo com as melhores evidências e práticas a perguntas como: O que está escrito? Quais são as evidências científicas? Que práticas estão consolidadas? Quais são as orientações das agências governamentais e organismos internacionais? Quem são os especialistas? Quem possui problema similar? etc.

Inseridos em contextos informados, autoridades, gestores, professores, pesquisadores, alunos, profissionais, técnicos e usuários têm oportunidade de tomar melhores decisões, de aprender continuamente ao receber $e$ intercambiar informação atualizada, de aumentar o seu conhecimento $e$ conseqüentemente sua capacidade de ação. Quando esta condição é apropriada por boa parte dos indivíduos dentro de um determinado contexto, a tendência é aumentar a eficiência, a eficácia e a qualidade do seu desempenho, competências essas indispensáveis nos serviços de saúde. O desafio que se apresenta é tornar sustentáveis estes fluxos locais de informação. Como se percebe na gestão das redes de instituições, esta condição é alcançada quando as instituições passam a operar na rede (interna e externa) as suas fontes $e$ fluxos de informação relacionadas com a sua função e objetivos.

A gestão do funcionamento da BVS baseia-se em uma arquitetura de fontes e fluxos de informação, com três dimensões principais:

- os domínios de produção, organização, circulação e uso de informação e conhecimento em saúde, ou seja, a natureza da informação;

- as funções ou finalidades das fontes de informação na comunicação em saúde, isto é, os diferentes tipos de fontes em relação a formato, conteúdo e sua aplicação prevista;

- a estruturação das fontes de informação para o armazenamento e comunicação na Internet na modalidade de serviços de domínio público orientados ao conceito de web semântico, no qual a informação e o conhecimento contextualizados estão ubiqüamente disponíveis para uso (Berners-Lee et al., 2001).

\section{Conclusão}

A construção coletiva da Biblioteca Virtual em Saúde, cuja evolução nos campos conceitual e operativo foi descrita neste documento, avança decisivamente como modus operandi consistente de trabalho cooperativo em rede na produção de fontes e fluxos de informação cientifica, técnica e factual em saúde. Ela envolve centenas de instituições de todos os países da América Latina e a maioria da ilhas do Caribe, em um movimento de cooperação técnica internacional que inclui progressivamente mais e mais instituições e contextos dos sistemas nacionais de pesquisa, educação e atenção à saúde. A participação da OPAS/OMS é essencial nesta evolução e remonta à sua origem, quando, respondendo às demandas dos países, e com o apoio decisivo do Brasil, criou em 1967 a BIREME como centro especializado em informação em ciências da saúde para liderar e coordenar esta cooperação técnica.

A sustentação política, institucional e financeira desse trabalho cooperativo que persiste crescendo por quase quatro décadas é, sem dúvida, consequência 
de um longo esforço dos países, individualmente e no seu conjunto, por meio da BIREME, em assegurar as condições, ainda que mínimas em muitos casos, para o desenvolvimento da comunicação científica e técnica na região, complementado e integrando-as com as fontes e fluxos dos paises desenvolvidos, promovendo assim condições concretas para a democratização da informação e conhecimento em saúde. É importante notar que são os paises que definem as políticas assim como a contribuição e aplicação de recursos que dirigem e financiam o funcionamento regular da OPAS, e, em particular, da BIREME. Nesse sentido, a função, evolução e desempenho da BIREME na liderança e coordenação do programa de cooperação em informação científica $e$ técnica deve ser apropriado como uma obra coletiva dos paises. Por isso mesmo uma linha de ação sistêmica da BIREME é reproduzir-se em sua funcionalidade no âmbito nacional.

Este esforço dos países que culminou a partir de 1998 na BVS, como espaço virtual na Internet, para onde convergem e interagem as ações dos produtores, intermediários e usuários de informação, o que, como vimos, renova e expande continuamente a cobertura do seu modus operandi centrado no trabalho cooperativo em torno a produtos, serviços e eventos de informação, que são de propriedade comum e de domínio público. Operados com acesso universal na BVS eles constituem referência internacional indentificados em uma lista de siglas como são LILACS, DeCS, SCAD, SciELO, REPIDISCA, CRICS etc. Estas fontes de informação reproduzem-se nacionalmente nos países e localmente nas instituições. Este processo persistente de interoperação local, nacional, regional e internacional, utilizando metodologias e padrões compatíveis, em sintonia com os paradigmas contemporâneos de gestão de informação $e$ conhecimento, constitui a essência do desempenho positivo da cooperação técnica nas últimas três décadas desde a fundação da BIREME. E é mister aprofundar esta interoperação ampliando, por um lado, a inclusão dos diferentes contextos de saúde para operarem na BVS como ambientes aprendizes, e, por outro lado, o uso das tecnologias de informação em torno da Internet. Este encaminhamento vai ao encontro da concepção e proposta explicitadas por Lévy de que os processos de produção e democratização do conhecimento devem enriquecer o sistema cognitivo humano com modos de organização coletiva assim como de tecnologias orientadas à comunicação e ao processamento de informação (Lévy, 1993; 1998).

A lição principal que a construção coletiva da BVS nos brinda é justamente o fato que ela é possível com toda a complexidade que significa a gestão das redes de instituições e das redes de fontes e fluxos de informação.

\section{Referências}

ACUÑA, H. R. Apresentação. O Index Medicus Latino-Americano. IMLA, v.1, n.1, 1979.

BERNERS-LEE, T; HENDLER, J.; LASSILA, O. The semantic web. A new form of Web content that is meaningful to computers will unleash a revolution of new possibilities. Sci. Am., n.17, may, 2002. Disponível em <http://cpdp.uab.es/documents/docencia/casanovas_pompeu/semantic_web.pdf>. Acesso em: 20 mai. 2005.

BIREME. Declaración de San José hacia la Biblioteca Virtual en Salud. In: Reunión del Sistema Latinoamericano y del Caribe de Información en Ciencias de la Salud, 6., Congreso Panamericano de Información en Ciencias de la Salud, 4, 1998. San José, Costa Rica, 1998. Disponível em: <http:// wuw.bireme.br/bvs/por/edeclar.htm>. Acesso em: 14 jun. 2005.

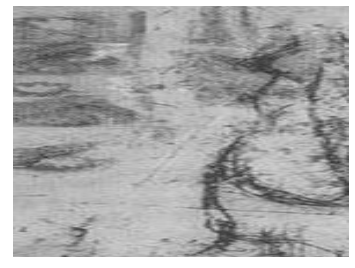


BIREME. Guia 2001 de desenvolvimento da Biblioteca Virtual em Saúde. São Paulo: BIREME, 2001. Disponível em: <http://www.bireme.br/crics5/E/guiabvs.htm>. Acesso em: 15 jun. 2005.

CASTRO, R. C. F.; PACKER, A. L.; CASTRO, E. Projeto LILACS/CD-ROM - Literatura Latino Americana e do Caribe em Ciência da Saúde em disco compacto. Rev. Bras. Bibliotecon. Document., v.22, n.1/2, p.105-14, 1989.

GIBBS, W.W. Lost science in the third world. Sci Am. v.273, n.2, p.76-83, 1995. Disponível em: <http:// www.sciamdigital.com/browse.cfm?ITEMIDCHAR=082AA6E7-13D1-4610-81F4-

EEC68867A24\&methodnameCHAR=\&interfacenameCHAR=browse.cfm\&ISSUEID_CHAR=A7B114FEF9D3-4600-903D-8E1B8CB8C54\&ArticleTypeSubInclude_BIT=0\&sequencenameCHAR=itemP $>$. Acesso em: 13 jun. 2005.

LÉVY, P. A inteligência coletiva: por uma antropologia do ciberespaço. São Paulo: Loyola, 1998.

LÉVY, P. Tecnologias da inteligência: o futuro do pensamento na era da informática. São Paulo: Editora 34, 1993.

DIERICKX, H.; HOPKINSON, A. (Ed.) Reference manual for machine-readable bibliographic descriptions. 2.ed. rev. Paris: UNESCO, 1981.

MC LUHAN, M. Understanding media: os meios de comunicação como extensões do homem.. São Paulo: Cultrix, 1974.

MCGARRY, K. O contexto dinâmico da informação. Brasília: Briquet de Lemos, 1999.

MENEGHINI, R. SciELO project and the visibility of peripheral scientific literature. Química Nova, v.25, p.155-6, 2002. Disponível em: <http://www.scielo.br/pdf/qn/v26n2/14980.pdf>. Acesso em: 5 jun. 2005.

NATIONAL LIBRARY OF MEDICINE. Programs and services. Fiscal year 1974. Disponível em: <http:// www.nlm.nih.gov/hmd/manuscripts/nlmarchives/annualreport/1974.pdf>. Acesso em: 14 jun. 2005.

NEGHME, A. Operations of the Biblioteca Regional de Medicina (BIREME). Bull. Med. Libr. Assoc., v. 63, n.2, p.173-9, 1975.

PACKER, A. L. ; CASTRO, E. (Eds). Biblioteca virtual en salud. São Paulo: BIREME, 1998.

PACKER, A. L.; BIOJONE, M.R.; ANTONIO, I. TAKENAKA, R. M.; GARCIA, A. P.; SILVA, A. C.; MURASAKI, R. T.; MYLEK, C.; REIS, O. C.; HÉLIDA, C. R. F. D. SciELO: uma metodologia para publicação eletrônica. Ci. Inf. Brasília, v.27 n.2, p. 109-21, 1998. Disponível em: <http://www.scielo.br/pdf/ci/v27n2/scielo.pdf>. Acesso em: 2 abr. 2005.

PARÍS, C. El animal cultural: la biología y cultura en la realidad humana. Barcelona: Editorial Crítica, 2000.

RUFF, B. The World Health Organization's role in strengthening health literature services in developing countries. In: SHARP, J. Selective libraries for medical schools in less developed countries. New York: The Rockfeller Foundation, 1980. p.157-67. [Working papers].

SONIS, A. Status and needs of the libraries of Latin American Medical Schools. In: BELLAGIO A. Selective libraries for medical schools in less developed countries. New York: The Rockfeller Foundation, 1980. p.45. [working papers].

THE NATIONAL ACADEMIES. Electronic scientific, technical and medical journal publishing and its implications. Report of a symposium 2004. Washington, DC: The National Academy of Sciences, 2004. Disponível em: <http://www.nap.edu/books/0309091616/html/>. Acesso em: 26 jun. 2005.

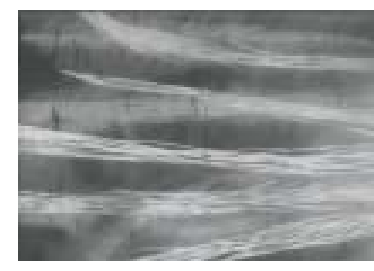


PACKER, A. L.

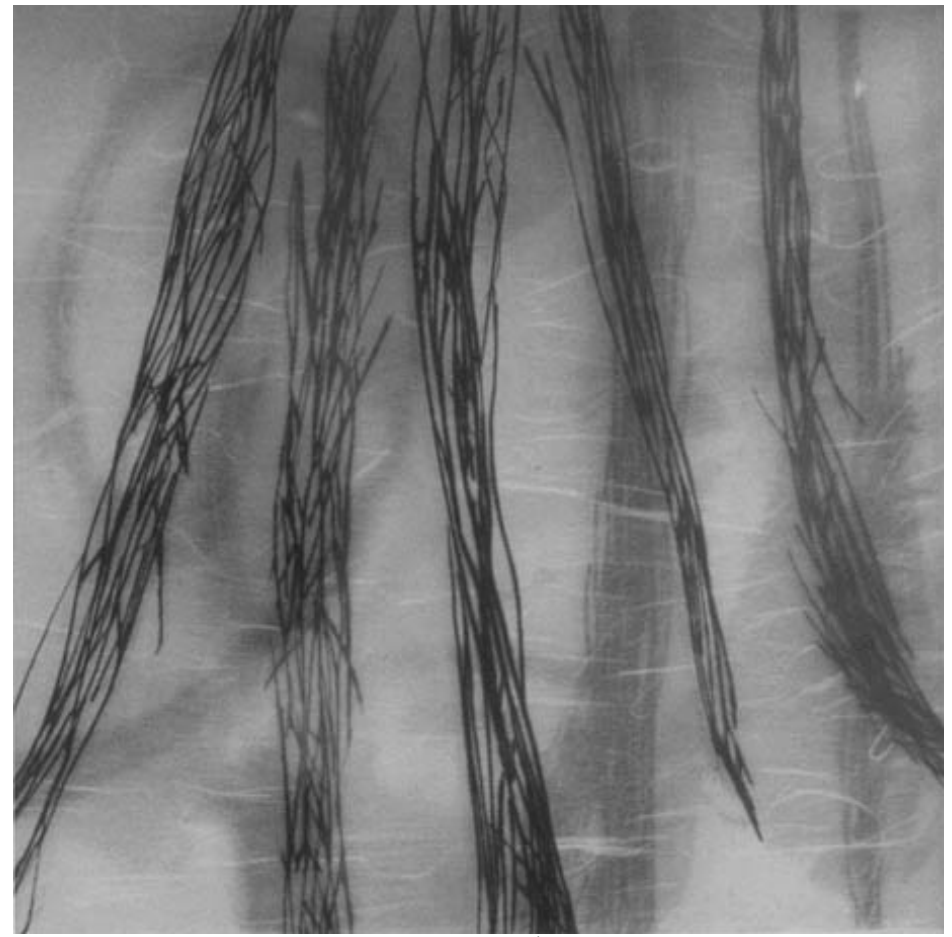

SÍLVIA MECOZZI, Sem título, 1997

PACKER, A. L. La construcción colectiva de la Biblioteca Virtual del área de Salud. Interface Comunic., Saúde, Educ., v.9, n.17, p.249-72, mar/ago 2005.

Se retoma el origen de la Biblioteca Virtual en el área de Salud (BVS) como producto de la evolución del programa de cooperación técnica en la información científica sobre la salud en América Latina y en el Caribe. Se analiza su conformación tecnológica como producto de la reestructuración de la comunicación científica promovida por la internet, destacando el perfeccionamiento conceptual y operacional del modelo de gestión colectiva de información y conocimiento en el espacio virtual y los desafíos de promover el acceso y uso democráticos de la información y del conocimiento actualizado en los procesos relacionados con la salud colectiva $e$ individual.

PALABRAS CLAVE: biblioteca virtual; bibliotecas médicas; sistemas de información; inteligencia colectiva. 